\title{
Vitamin D deficiency in critically ill children
}

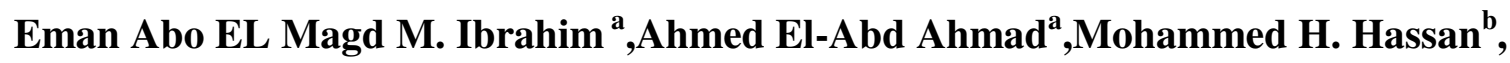 Nagwan I. Rashwan ${ }^{a}$}

${ }^{\text {a} P e d i a t r i c ~ D e p a r t m e n t, ~ Q e n a ~ F a c u l t y ~ o f ~ M e d i c i n e, ~ S o u t h ~ V a l l e y ~ U n i v e r s i t y . ~}$

${ }^{b}$ Medical biochemistryDepartment, Qena Faculty of Medicine, South Valley University.

\begin{abstract}
:
Background:In critical illness, there also is evidence of rapid falls in circulating $25(\mathrm{OH}) \mathrm{D}$ concentrations. So, we aim to assess the prevalence of VDD in a pediatric ICU (PICU) patients and to determine whether there is any relationship between VDD and illness severity and mortality.

Patients and methods:this is a case control study that included 40 children :20 patient admitted to pediatric intensive care unit in Qena university at time of the study(from January 2018 till December 2018) compared to 20 apparently healthy well-matched children regarding age and sex to be compared as controls.All patients subjected to: Full history,detailed physical examination,diagnostic modalities as: laboratory investigation and severity of illness was assessed with the pediatric risk of mortality III
\end{abstract}

Result: Our study included 40 child with the age of patientsrangedfrom5 monthsto12years withmean +/- SD $3.7 \pm 3$ year. Male patients represented70\%.In our study, the prevalence of vitamin $\mathrm{D}$ deficiency among critically ill children was $70 \%$ we did not findsignificant correlation between $25(\mathrm{OH})$ vitamin D and pediatric risk of mortality III (PRISM III)

Conclusion:Vitamin D Deficiency (VDD) prevalence was reported in $70 \%$ of the critically ill patients, and it was observed to be related to multiple organ dysfunctions and rapid clinicaldeterioration.

Keywords:vitamin D deficiency, pediatric critical illness.

\section{Introduction}

Vitamin D plays an important role in metabolism and homeostasis in the general population, nowadays there is a growing interest in its potential association with critical illness (Norman et al,2008).

In critical illness, there is acute drop of Vitamin Dserum concentrations owing to increased tissue demands and impaired compensatory mechanisms by inflammatory process and organ destruction that may prolong the pathophysiology of critical illness(McNally et al, 2012).

Although several studies from different pediatric ICUs (PICUs) around the world have been published revealing an increased prevelance of Vitamin D deficiency (VDD) in range of 30-71\%, (Ponnarmeni et al., 2016).

The question if vitamin $D$ deficiency(VDD) is involved in multiple organ dysfunction and mortalityis not answeredyet. Our study investigated the hypothesis that VDD might be related to higher severity scores and risk of mortality. The primary objective of this study was to estimate the prevalence of VDD in a group of critically ill children, and the secondary objective was to correlate vitamin D status with pediatric risk of mortality III (PRISM III) score.

\section{Patients and methods}


Our study included 40 children :20 patient admitted to pediatric intensive care unit in Qena university hospital at the time of the study from January 2018 till December 2018, compared to 20 apparently healthy well-matched children regarding age and sex as a control group

\section{Inclusion criteria}

Our study included all patient received treatment in pediatric intensive care unit of Qena University Hospitals in time of the study.

\section{Exclusion criteria}

We excluded patients who received vitamin $\mathrm{D}$ therapy during the last 6 months or refusing to participate in the study and cardiac surgical patients

\section{Study tools:}

After obtaining informed consent, all of the patients had been subjected to the following:

1-Full history was obtained from Parents about intake of vitamin D-containing drugs stressing on the onset and duration of the disease, manifestations suggesting disturbances in calcium metabolism, for example, bone pains, cramps of the hand or feet, fractures.

2-Detailed physical examination, Blood pressure measurement, patientheight, weight and BMI were recorded. Severity of illness was assessed within the first 24 $\mathrm{h}$ of PICU admission with the PRISM III score using 16 variables

3- Laboratory investigation

-Vitamin D samples were collected within the first $24 \mathrm{~h}$ of admission to the PICU,measurements of Vitamin D was performed using commercially available sandwich enzyme-linked immunosorbent assay (ELISA) kits, supplied by Chongqing Biopsies Co., Ltd (Chongqing, People's Republic of China) with the catalog numbers: BYEK1472, using microplate ELISA reader (EMR -500, USA).(Hassan et al 2018)( Kim et al 2013).

The serum 25-OHD level of:

- $\geq 30 \mathrm{ng} / \mathrm{ml}$ was considered optimal,

- $\leq 20 \mathrm{ng} / \mathrm{ml}$ was considered to have vitamin $\mathrm{D}$ deficiency,

- Vitamin D insufficiency was diagnosed at serum levels from 21 to $29 \mathrm{ng} / \mathrm{ml}$.

(Holick et al.,2011)

Phosphorous,ionizedcalcium, andalkaline phosphatase

$-\mathrm{C}$ reactive protein

- Blood culture

- Arterial blood gases

\section{Statistical analysis:}

All patients had been analyzed using Statistical package for Social Sciences (SPSSV26).

\section{Results}

Table 1: Demographic data of critically ill patients and control

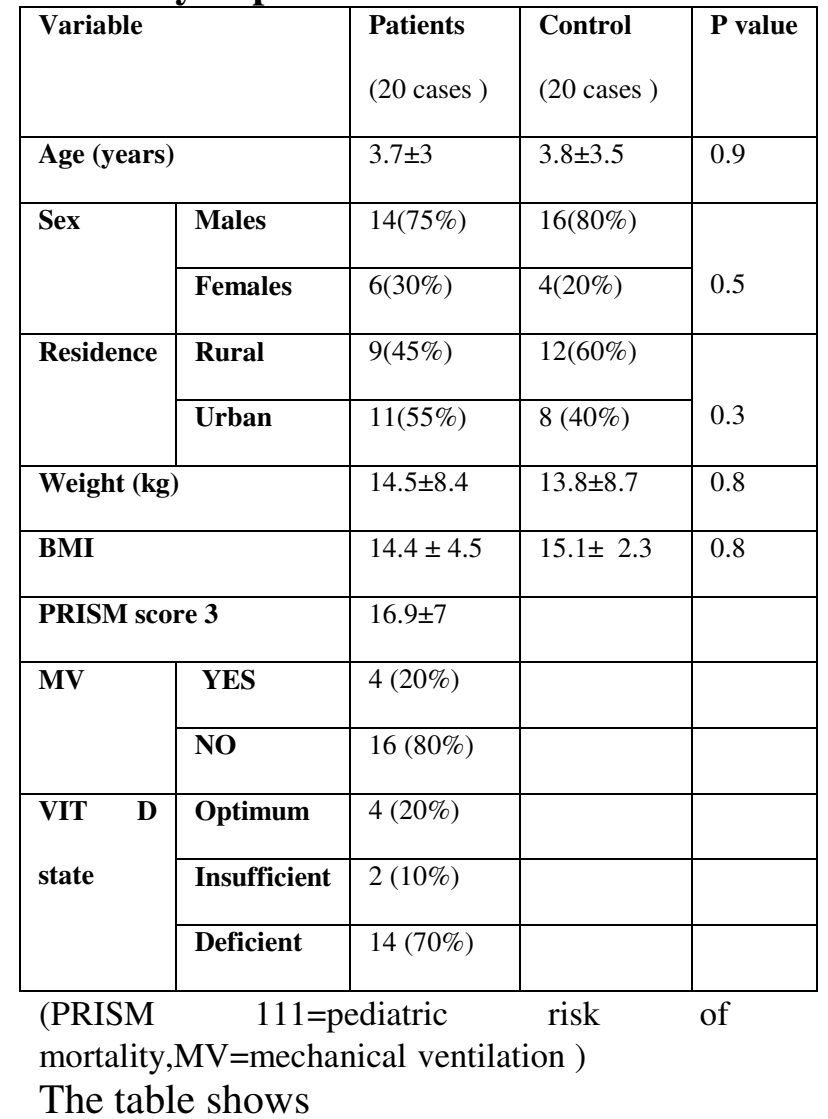


- Mean age is $3.7 \pm 3$ year.

- Male patients represented $70 \%$.

- Residence of most patient was urban (11 cases, 55\%)

- BMI of patient ranged with a mean is $16.9 \pm 7$.

- $20 \%$ of patient were connected to mechanical ventilation

- PRISM score ranged with a mean is $16.9 \pm 7$

Table 2 : Mean \pm SD of laboratory data of patients and control.

\begin{tabular}{|c|c|c|c|c|}
\hline \multicolumn{2}{|c|}{ Variable } & $\begin{array}{l}\text { Patients } \\
\text { (20 cases ) }\end{array}$ & $\begin{array}{l}\text { Control } \\
(20 \text { cases })\end{array}$ & P value \\
\hline \multicolumn{2}{|c|}{$\begin{array}{l}\text { 25OH VIT D level } \\
(\mathrm{ng} / \mathrm{ml})\end{array}$} & $19.2 \pm 15.1$ & $35.9 \pm 6.7$ & 0.03 \\
\hline \multicolumn{2}{|l|}{$\begin{array}{l}\text { PTH } \\
\text { (ng/l) }\end{array}$} & $40.8 \pm 16.5$ & $26.7 \pm 10.5$ & 0.09 \\
\hline \multicolumn{2}{|c|}{$\begin{array}{c}\text { ionized ca } \\
(\mathrm{mmol} / \mathrm{l})\end{array}$} & $1.1 \pm .1$ & $1.2 \pm .05$ & 0.8 \\
\hline \multicolumn{2}{|c|}{$\begin{array}{l}\text { Phosphate } \\
(\mathrm{mmol} / \mathrm{l})\end{array}$} & $3.8 \pm .3$ & $4.9 \pm .8$ & 0.000 \\
\hline \multicolumn{2}{|l|}{$\mathbf{P H}$} & $7.3 \pm .1$ & $7.4 \pm .05$ & 0.1 \\
\hline \multicolumn{2}{|c|}{$\begin{array}{l}\mathrm{CO2} \\
(\mathrm{mm} \mathrm{Hg})\end{array}$} & $28.4 \pm 14$ & $20.6 \pm 1.7$ & 0.1 \\
\hline \multicolumn{2}{|c|}{$\begin{array}{l}\mathrm{HCO3} \\
(\mathrm{mEq} / \mathrm{L})\end{array}$} & $14.8 \pm 6.7$ & $20.6 \pm 1.7$ & 0.07 \\
\hline \multicolumn{2}{|l|}{$\begin{array}{l}\text { CRP } \\
(\mathbf{m g} / \mathrm{l})\end{array}$} & $24.2 \pm 19.6$ & $4.6 \pm .5$ & 0.04 \\
\hline \multirow[t]{2}{*}{$\begin{array}{l}\text { Blood } \\
\text { culture }\end{array}$} & $\begin{array}{l}\begin{array}{l}\text { No } \\
\text { growth }\end{array} \\
\end{array}$ & 14 & & \\
\hline & Growth & 6 & & \\
\hline
\end{tabular}

This table shows:

- laboratory results of the studied group compared to control group , shows that $25 \mathrm{OH}$ vitamin $\mathrm{D}$,

\section{PRISM 111}

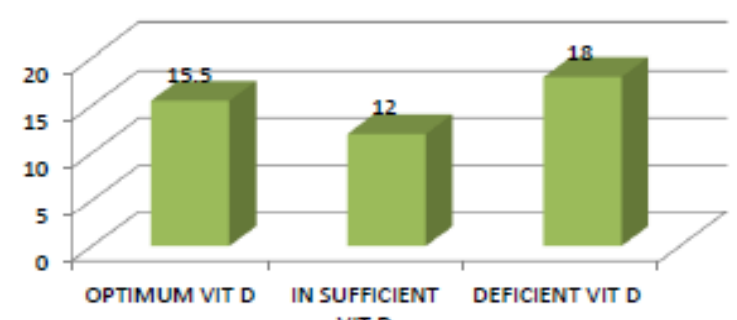

phosphate and CRP have highly significant difference between patient group and control group .

- Also shows that PTH, ionized $\mathrm{Ca}$, $\mathrm{PH}, \mathrm{CO} 2$, and $\mathrm{HCO} 3$ have no significant difference between the two groups

\section{Figure(1): $\quad$ showing relation PRISM111and vitamin D level}

This figure shows:The mean of pediatric risk of mortality score 111 higher in patient of vitamin D deficiency

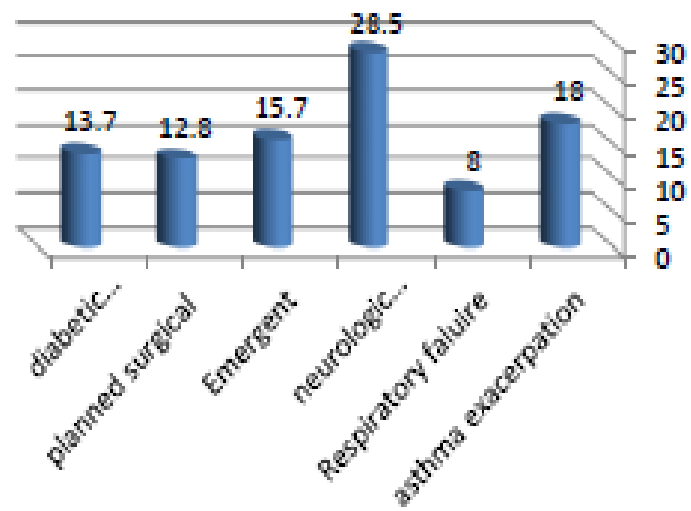

Figure 2: vitamin D level associated with PICU admission

This figure shows: a mean of vitamin D level was the lowest in patients with respiratory failure, surgical problems and diabetic ketoacidosis

Table (3): Relation between vitamin D deficiency status and markers of illness severity and intensive care unit outcome.

\begin{tabular}{|l|l|l|l|l|l|}
\hline \multicolumn{2}{|l|}{ Variable } & N & $\%$ & $25(\mathrm{OH}) \mathrm{D}$ & P value \\
\hline Mortality & Died & 4 & $20 \%$ & $13.3 \pm 14.4$ & \multirow{2}{*}{0.4} \\
\cline { 2 - 5 } & Improved & 16 & $80 \%$ & $20.6 \pm 15.3$ & \\
\hline $\begin{array}{l}\text { Mechanical } \\
\text { ventilation }\end{array}$ & Yes & 4 & $20 \%$ & $13.3 \pm 14.4$ & \multirow{2}{*}{0.4} \\
\cline { 2 - 5 } & No & 16 & $80 \%$ & $20.6 \pm 15.3$ & \\
\hline $\begin{array}{l}\text { Vasopressor } \\
\text { use }\end{array}$ & Yes & 7 & $35 \%$ & $13.7 \pm 11.7$ & \multirow{2}{*}{0.2} \\
\cline { 2 - 5 } & No & 13 & $65 \%$ & $22.1 \pm 16.2$ & \\
\hline
\end{tabular}




\begin{tabular}{|c|c|c|c|c|c|}
\hline \multirow[t]{2}{*}{ Infection } & Yes & 6 & $30 \%$ & $17.1 \pm 10.5$ & \multirow{2}{*}{0.6} \\
\hline & No & 14 & $70 \%$ & $21 \pm 16.7$ & \\
\hline \multirow[t]{3}{*}{ Vitamin D } & Deficient & 14 & $70 \%$ & $10.9 \pm 4.9$ & \multirow{3}{*}{0.03} \\
\hline & Optimum & 4 & $20 \%$ & $45.1 \pm 10$ & \\
\hline & Insufficient & 2 & $10 \%$ & $24.9 \pm 1.3$ & \\
\hline
\end{tabular}

This table shows:

- mean of vitamin D is less in died patient compared to improved patient.

- It is less in patients connected to mechanical ventilation compared to those who were not connected to mechanical ventilation

- Also, it is less in patients with proved infection and those who used vasopressor.

\section{Discussion}

Our study included 40 children :20 patient admitted to pediatric intensive care unit in Qena university hospital at the time of the study compared to 20 healthy well-matched children regarding age and sex as a control group age of them ranged from 5 months to12 years with mean $3.7+\_3 \mathrm{yr}$.

Badawi et al 2017 studied 88 children from 1 month to 12 years of age, a median of 36 months.

Male patients in our current study represented $70 \%$. This is similar to Badawi et al 2017 who found that 57\% were males.

In our study neurologic disorders were the most common diagnosis in $35 \%$. Respiratory disorders $30 \% \quad(15 \%$ respiratory failure and $15 \%$ for status asthmaticus), diabetic ketoacidosis in $15 \%$, elective postoperative illness in $10 \%$. This is in contrast to Badawi et al 2017 where Respiratory disorders were the most common diagnosis in $45 \%$ (43\% pneumonia and $2 \%$ for status asthmaticus), neurological disorders in $22.7 \%$ heart failure in $10.5 \%$, diabetic ketoacidosis in $6.8 \%$, elective postoperative illness in $4.5 \%$,

Admission diagnoses among the studied children included a variety of medical

critical conditions, whereas postoperative patients comprised only $10 \%$ with exclusion of cardiac surgical patients, unlike McNally et al 2012 and Ripple et al 2012; both had a large category of postoperative cardiac and surgical diagnoses. Madden et al 2012. excluded cardiac surgical cases because of the effect of cardiac bypass on vitamin D levels.

In our study ventilated patients represented $20 \%$ of the admissions. We found no relation between vitamin $\mathrm{D}$ and need for mechanical ventilation. In contrast to Ebenezer et al 2014 where $51 \% \%$ of patients were ventilated and found that Children who were ventilated during their PICU stay had a significantly lower median serum $25(\mathrm{OH}) \mathrm{D}$ level than those who were not ventilated.

In our study proved infection by blood culture was present in $30 \%$ of cases, similar to Ebenezer et al 2014 in which microbiological confirmation was present in $37 \%$ of them, neither our study norEbenezer et al 2014 could demonstrate an association between vitamin D status and infection in these groups of critically ill children.

In our study mortality rate was $20 \%$, the high mortality of $20 \%$ has many contributing factors such as delayed PICU admission due lack of beds, poor access to appropriate care and high percentage of multiple organ failure. GemkeandBonsel(1995) in a multicenter study showed a mean $7.1 \%$ mortality (range $=1-10 \%$ ) in PICU patients; one of the reasons for this variable mortality was related to the different severity of disorders. ElNawawy,2003 showed 38\% PICU mortality, but in India (Thukraletal,2006) this was 35\% and in Argentina (Eulmesekian et al, 2007 ) it was lower $(2.6 \%)$.

In our study, the prevalence of vitamin D deficiency among critically ill children 
was $70 \%$. Another $10 \%$ of children had vitamin $\mathrm{D}$ insufficiency. This is higher than the reported prevalence of $29.5 \%$ from Brazil (Rey et al, 2014) and 34.5 and $40.1 \%$, among critically ill Australian and Canadian children respectively and similar to the prevalence of $69 \%$ reported by Madden et al. from North America (Madden et al, 2012)

In our study, we did not find significant correlation between $25(\mathrm{OH})$ vitamin D and pediatric risk of mortality III (PRISM III) , need for mechanical ventilation and inotropes these results similar to Reye, Ripple and Ponnarmeni which could not find anassociation between (PRISM III) and vitamin D levels.

In contrast to Madden et al,2012 and McNally et al,2012 in which25 (OH) D levels was inversely associated with PRISM III score on admission among PICU patients.

Also in contrast to Braun et al, 2011 who showed a significant association between low serum $25(\mathrm{OH})$ D concentrations and an increase in blood culture positivity .we could not find such relation in our study.

In our study,the recorded values of vitamin D showed lower levels among patients with diabetic ketoacidosis, respiratory faluire, but this was just an observation that was not feasible for statistical analysis because of the small sample size of the subgroups.

The role of vitamin $\mathrm{D}$ in the pathogenesis of diabetes is well known but whether the marked deficiency had a role in diabetic ketoacidosis precipitation or whether this is a sequence of the critical illness still needs to be investigated. (Mutlu et al, 2011).
Further research in category specific critical illness would be helpful to explore the possible relation between VDD and deterioration of chronic illnesses such as cardiomyopathy, Asthma and DKA.

\section{Conclusions:}

Vitamin D Deficiency (VDD) prevalence was reported in $70 \%$ of the critically ill patients, and it was observed to be related to multiple organ dysfunctions and rapid clinical deterioration.

\section{Study Limitations}

Mainly arethe relatively small number of patients and being a single center study so that some subgroup comparisons may have lacked power to detect significant differences for selected variables, Further research in the category specific critical illness especially on larger number of patients and on other patients' categories are recommended and would be helpful to explore the possible relation between VDD and deterioration of chronic illnesses

\section{References:}

Braun A, Chang D, MahadevappaK, Gibbons F K , Liu Y,Giovannucci E, Christopher K B. (2011). Association of low serum 25hydroxyvitamin D levels and mortality in the critically ill*. Critical Care Medicine, 39: 671-677.

CzarnikT,Czarnik A, Gawda R, Gawor M, Piwoda M, Marszalski $M$, CzuczwarM. (2018). Vitamin D kinetics in the acute phase of critical illness: A prospective observational study. Journal of Critical Care 43: 294-299.

El-NawawyA. (2003). Evaluation of the Outcome of Patients Admitted to the Pediatric Intensive Care Unit in Alexandria Using the Pediatric Risk of 
Mortality (PRISM) Score. Journal of Tropical Pediatrics 49:109-114.

Eulmesekian PG, Pérez A, Minces PG, Ferrero H. (2007) Validation of pediatric index of mortality 2 (PIM2) in a single pediatric intensive care unit of Argentina. PediatrCrit Care Medicine, 8:54-57.

GemkeRJ,BonselGJ.(1995)Comparativ eassessmentofpediatric intensive care: a -23. 17 national multicenter study. Pediatric Intensive Care Assessment of Outcome (PICASSO) Study Group. Crit Care Med 23:238-245

\section{Hassan MH,Ibrahim HM, El-Taieb} MA. (2018).25-Hydroxy cholecalciferol, anti-Müllerian hormone, and thyroid profiles among infertile men. The Aging Male, 1-7.

\section{Ebenezer K, Job V, AntonisamyB} ,Dawodu A, Manivachagan MN, Steinhoff M. (2015).Serum Vitamin D Status and Outcome among Critically Ill Children Admitted to the Pediatric Intensive Care Unit in South India. The Indian Journal of Pediatrics, 83: 120125 .

Kim TH, Lee BH, Lee HM, Lee SH, ParkJO, KimHS,etal.(2013)Preval enceof vitamin D deficiency in patients with lumbar spinal stenosis and its relationship with pain. Pain Physician 16:165-76.

MaddenK,FeldmanHA,SmithEM,Gord onCM, KeislingSM, SullivanRM,et al.(2012) Vitamin D deficiency in critically ill children. Pediatrics 130:421428.

McNally JD,Menon K, Chakraborty P, Fisher L, WilliamsKA, Al-Dirbashi OY. (2012).Association of Vitamin D
Status with Pediatric Critical Illness. PEDIATRICS, 130(3): 429-436.

MutluA,MutluGY,Özsu E, Çizmecioğlu FM, Hatun Ş.(2011). Vitamin D deficiency in children and adolescents with type 1 diabetes. J Clin Res PediatrEndocrinol 3:179-183. 1687-4625

Nora El Said Badawia,Hebat Allah FadelAlgebalyb, Riham EI Sayedc, EmanSayed Abu Zeidb (2017). Vitamin $\mathrm{D}$ deficiency in critically ill children Kasr Al Ainy Med J 23:6-11

Norman, A. W. (2008).From vitamin D to hormone D: fundamentals of the vitamin D endocrine system essential for good health. The American Journal of Clinical Nutrition, 88(2): 491S-499S.

PonnarmeniS, Kumar Angurana S, Singhi S, Bansal A, Dayal D, Kaur R, VermaAttriS. (2016).Vitamin D deficiency in critically ill children with sepsis. Paediatrics and International Child Health, 36(1): 15-21.

Rey C, Sánchez-Arango D, López-Herce J, Martínez-Camblor, P, García-Hernández I, Prieto B, PallaviciniZ. (2014).Vitamin D deficiency at pediatric intensive care admission. Jornal de Pediatria, 90(2): 135-142.

\section{RippelC,South M, Butt WW,} Shekerdemian LS. (2012).Vitamin D status in critically ill children. Intensive Care Medicine, 38(12):2055-2062.

ThukralA,LodhaXX,Irshad M, Arora NK. (2006)Performance of pediatric risk of mortality (PRISM), pediatric index of mortality (PIM) and PIM2 in a pediatric intensive care unit in a developing country. PediatrCrit Care Med 7:356361. 